\title{
Wetting Behavior and Reactivity Between AlTi6 Alloy and Carbon Nanotubes
}

\author{
M. Homa, N. Sobczak, J.J. Sobczak, J. Morgiel, S. Seal, R. Nowak, and G. Bruzda
}

\author{
(Submitted November 17, 2015; in revised form January 12, 2016; published online February 4, 2016)
}

\begin{abstract}
Wetting behavior between molten AITi6 alloy and nanoporous carbon substrate (carbon nanotubes paper) was investigated by a sessile drop method in vacuum at 800,900 , and $1000{ }^{\circ} \mathrm{C}$. In order to avoid the effect of native oxide film on metal sample, an advanced capillary purification technique coupled with non-contact heating was applied. The AITi6 drop did not wet the MWCNT paper immediately after deposition on the substrate at $800{ }^{\circ} \mathrm{C}$, forming a contact angle of $\theta=153^{\circ}$. The increase in temperature up to $900{ }^{\circ} \mathrm{C}$ and holding the system for $15 \mathrm{~min}$ also did not affect the contact angle $(\theta=153 \pm 1)$. Further heating above $930{ }^{\circ} \mathrm{C}$ at a rate of $5^{\circ} \mathrm{C} / \mathrm{min}$ caused a gradual lowering of contact angle down to $\sim 130^{\circ}$ and after about 10 min interaction at $1000{ }^{\circ} \mathrm{C}$, it reached the final value of $123^{\circ}$. Structural investigations of solidified sessile drop AITi6/MWCNT couple by scanning and transmission electron microscopy showed that high-temperature interaction between MWCNTs and molten AITi6 alloy is accompanied with liquid metal infiltration of MWCNT substrate, fragmentation of MWCNTs, and formation of TiC in the form of rod-like crystallites and fine particles uniformly distributed in the metal matrix. The mechanism of MWCNT $\rightarrow$ TiC transformation in the AITi6/MWCNT system by high-temperature liquid-assisted process is discussed.
\end{abstract}

Keywords AlTi6, carbon nanotubes, interfaces, MWCNT, reactivity, rod-like $\mathrm{TiC}$, sessile drop

\section{Introduction}

Metal-ceramic composites present a creative solution to the ever-increasing demand for materials with improved structural and operational properties (Ref 1-17). Various carbon reinforcements have been used for synthesis of metal-ceramic composites, including graphite (Ref 1,2$)$, carbon fibers $(\mathrm{CFs})$ (Ref 1-5), carbon nanotubes (CNTs) (Ref 2, 3, 5-12), carbon foam (Ref 2, 3) graphene (Ref 12, 13), fullerene (Ref 14), diamond (Ref 2, 3, 15, 16), and glassy-like carbon (Ref 17). The introduction of graphite particles into a metal matrix improves tribological properties and assures self-lubrication of metal-graphite composites (Ref 1), while the introduction of

This article is an invited submission to JMEP selected from presentations at the Symposium "Wetting and High-Temperature Capillarity," belonging to the Topic "Joining and Interfaces" at the European Congress and Exhibition on Advanced Materials and Processes (EUROMAT 2015), held September 20-24, 2015, in Warsaw, Poland, and has been expanded from the original presentation.

Electronic supplementary material The online version of this article (doi:10.1007/s11665-016-1919-5) contains supplementary material, which is available to authorized users.

M. Homa, J.J. Sobczak, R. Nowak, and G. Bruzda, Foundry Research Institute, 73 Zakopianska st., 30-418 Krakow, Poland; N. Sobczak, Foundry Research Institute, 73 Zakopianska St., 30-418 Kraków, Poland and Motor Transport Institute, 80 Jagiellonska St., 03-301 Warsaw, Poland; J. Morgiel, Institute of Metallurgy and Materials Science, Polish Academy of Sciences, 25 Reymonta St., 30-059 Kraków, Poland; and S. Seal, University of Central Florida, P.O. Box 162455, Orlando, FL 32816. Contact e-mail: marta.homa@ iod.krakow.pl. diamond particles significantly increases hardness as well as thermal and electrical conductivity (Ref 2, 3, 15, 16). CFs and CNTs are characterized by unique combination of mechanical and thermo-physical properties, i.e., high tensile strength and modulus of elasticity coupled with low density and high thermal and electrical conductivity. Thus, the application of CNTs as reinforcement of aluminum and its alloys is attractive for synthesis of advanced light-weight engineering and thermal management materials with enhanced performance, reliability, and life cycle, particularly for use in automotive, aerospace, energy, and electronic industries (Ref 1-6).

Among different manufacturing methods used for the production of aluminum matrix composites, liquid-assisted processes such as casting techniques are widely applied due to their relatively low cost and simplicity. Therefore, information on factors affecting high-temperature interaction between liquid $\mathrm{Al}$ and different carbon materials, particularly their wetting properties and reactivity, is of vital practical importance. One of the more frequently used casting processes involves the preparation of a metal-ceramic suspension by introduction of particulate reinforcement (particles, short fibers) into molten metal and its crystallization. For this process, an important issue is to obtain uniform distribution of reinforcement in the metal matrix because of the two accompanying phenomena taking place in metal-ceramic slurry: (1) the agglomeration of carbon phase due to the lack of wettability by the liquid $\mathrm{Al}$ and its most alloys at industrially important temperatures and (2) flotation of carbon phase due to the substantial difference in the density of the reinforcement and metal matrix. Another widely used casting technique is based on infiltration of porous preform with molten metal matrix. For this purpose, either external pressure or improvement in wetting is needed because of the lack of wettability in $\mathrm{Al} / \mathrm{C}$ system at industrially important temperatures below $800{ }^{\circ} \mathrm{C}$ (Ref 18-25).

An important issue associated with the production of Almatrix composites containing carbon phase is related with high reactivity between $\mathrm{Al}$ and different carbon materials. It leads to 
the formation of $\mathrm{Al}_{4} \mathrm{C}_{3}$ at the $\mathrm{Al} / \mathrm{C}$ interfaces evidenced with graphite (Ref 1, 2, 20-27), carbon fibers (Ref 1-5), glassy-like carbon (Ref 21-24), diamond (Ref 2, 3, 15), CNT (Ref 5-10), and graphene $(\operatorname{Ref} 12,13)$ :

$4 \mathrm{Al}+3 \mathrm{C}=\mathrm{Al}_{4} \mathrm{C}_{3}$.

Although the presence of thin $\mathrm{Al}_{4} \mathrm{C}_{3}$ layer contributes to better interfacial bonding, the formation of $\mathrm{Al}_{4} \mathrm{C}_{3}$ may cause a dramatic decrease in corrosion resistance of such composites since $\mathrm{Al}_{4} \mathrm{C}_{3}$ is fragile and easily reacts with moisture to form gaseous product $\mathrm{CH}_{4}$ - from the reaction:

$\mathrm{Al}_{4} \mathrm{C}_{3}+6 \mathrm{H}_{2} \mathrm{O}=2 \mathrm{Al}_{2} \mathrm{O}_{3}+3 \mathrm{CH}_{4-}$.

The problem of the lack of physico-chemical compatibility between $\mathrm{Al}$ and carbon phase can be overcome by (1) the application of technological coatings improving wetting (e.g., $\mathrm{Cu}, \mathrm{Ni}, \mathrm{Si}, \mathrm{Ti}, \mathrm{W}$ (Ref 1-3, 15, 18, 19)), (2) special surface treatment of carbon phase (e.g., etching of diamond in acids (Ref 16)), (3) alloying aluminum with carbon-forming elements (e.g., Si, Ti, Cr, W, and Mo (Ref 1-3, 17, 20-27)), (4) assuring kinetic compatibility in the $\mathrm{Al} / \mathrm{C}$ system through a dramatic decrease in contact time (Ref 4), and (5) electromagnetic enhancement (Ref 25).

By applying the sessile drop method at $750-1150{ }^{\circ} \mathrm{C}$, Sobczak et al. (Ref 4, 18-22, 26, 27) performed systematic studies on the effect of alloying $\mathrm{Al}$ with $\mathrm{Ti}$ on its hightemperature interaction with different carbon allotropic forms, including graphite (Ref 18-21, 26, 27), glassy-like carbon (Ref $4,21,22)$, and carbon fibers (Ref 4). It was demonstrated that the introduction of $\mathrm{Ti}$ into aluminum matrix may suppress or even completely prevent the formation of undesired $\mathrm{Al}_{4} \mathrm{C}_{3}$ since $\mathrm{Ti}$ from the alloy reacts with $\mathrm{C}$ to form very fine $\mathrm{TiC}$ particles instead of $\mathrm{Al}_{4} \mathrm{C}_{3}$ phase:

$\mathrm{Ti}+\mathrm{C}=\mathrm{TiC}$.

However, the final structure and phase composition of Al-Ti/ $\mathrm{C}$ couples were significantly affected not only by temperature, time of contact, amount of $\mathrm{Ti}$, and type of carbon material but also by the structure and particularly porosity of carbon substrate used in the study. Thus, it was demonstrated that, depending on processing variables and porosity, either $\mathrm{Al}_{4} \mathrm{C}_{3}$ or $\mathrm{TiC}$ or even both these phases can be formed. From this point of view, it is interesting to understand how a very specific morphology of CNTs may affect the formation of $\mathrm{TiC}$ precipitates from molten Al-Ti alloy and whether or not the reactively formed $\mathrm{TiC}$ will grow by duplication the initial morphology of starting CNTs.

Therefore, in this paper, the mechanism of the nucleation and growth of $\mathrm{TiC}$ due to interaction between CNT substrate and molten $\mathrm{Al}$ containing $\mathrm{Ti}$ was examined through investigation of their high-temperature wetting behavior and reactivity.

\section{Experimental}

\subsection{Materials}

The materials used were AlTi6 alloy and MWCNT paper. The as-received alloy contained $5.9 \mathrm{wt} . \% \mathrm{Ti}$ and was extruded rod from KBM Master Alloys B.V. (the Netherlands). MWCNT paper of $0.15 \mathrm{~mm}$ thickness was fabricated from MWCNTs (the amount of amorphous carbon and $\mathrm{Fe}$ nanoparticles $<1.0 \%$ ) synthesized by the catalytic vapor decomposition method as described elsewhere (Ref 28). For testing, a substrate of $15 \times 15 \mathrm{~mm}$ size was cut from the as-received paper.

\subsection{Methods}

The sessile drop (SD) method (Ref 18-22) was applied for investigation of high-temperature wetting behavior of molten AlTi6 alloy on MWCNT paper using experimental complex described in detail in Ref 29. In order to avoid the effects of native oxide film on metal sample as well as heating history of alloy/substrate couple on wetting behavior, the research was performed under UHV using non-contact heating of a metal and a substrate coupled with capillary purification (cp) as described in Ref 18, 21, 22, 29.

For this purpose, directly before loading into a vacuum chamber, the sample of AlTi6 alloy was cleaned mechanically and ultrasonically in isopropanol and placed inside a ceramic capillary positioned above the MWCNT substrate. The substrate was positioned on alumina support located inside tantalum resistance heater of the vacuum chamber. After evacuation of gases and getting vacuum of $p=1.45 \times 10^{-5}$ mbar by means of a turbomolecular pump, the setup was heated according to the temperature profile shown in Fig. 1. During the whole course of wettability study, the type and amount of residual gases in the vacuum chamber were monitored in real time using quadrupole Pfeiffer Prisma QMS200 device.

The sessile drop tests were performed using an AlTi6/ MWCNT couple at the three temperatures of 800,900 , and $1000{ }^{\circ} \mathrm{C}$, marked as stages I, II, and III in Fig. 1, respectively. After reaching the first test temperature $\left(800{ }^{\circ} \mathrm{C}\right)$, the AlTi6 drop was dispensed by squeezing the liquid metal through a hole in the capillary. After testing at the last temperature $\left(1000{ }^{\circ} \mathrm{C}\right)$, the couple was cooled at a rate of about $10^{\circ} \mathrm{C} / \mathrm{min}$.

During wettability tests, the images of the drop/substrate couple were in situ recorded using high-speed high-resolution camera MC1310 with a rate of 10 frames/s. The collected images were used for estimation of the contact angle values with the use of a special software ASTRA2 (IENI-CNR, Italy (Ref 30, 31)) as well as for making a real-time movie of high-temperature test performed (see Supplementary Video 1). The software enables the determination of the contact angle on the left and on the right side of a drop by an automatic image analysis with systematic uncertainty of the contact angle less than \pm 2 .

Structural characterization was performed on both the starting materials and the solidified sessile drop AlTi6/CNT couple using the following techniques:

(1) digital light microscopy (LM) using VHX-700F Keyence device allowing 3D-imaging;

(2) scanning electron microscopy (SEM) using Quanta 3D;

(3) transmission electron microscopy using FEI TECNAI SuperTWIN (200 keV) FEG device equipped with integrated energy-dispersive spectroscopy (EDS) system. The observations were performed using bright-field (BF), high-resolution (HR), as well as scanning transmission electron microscopy-high-angle annular darkfield (STEM-HAADF) techniques. The thin foil for TEM studies was cut out with FEI QUANTA 200 3D focused ion beam (FIB) equipped with Omnioprobe liftout system. The surface of the investigated material was separated from the platinum masking bar with an additional carbon layer. 


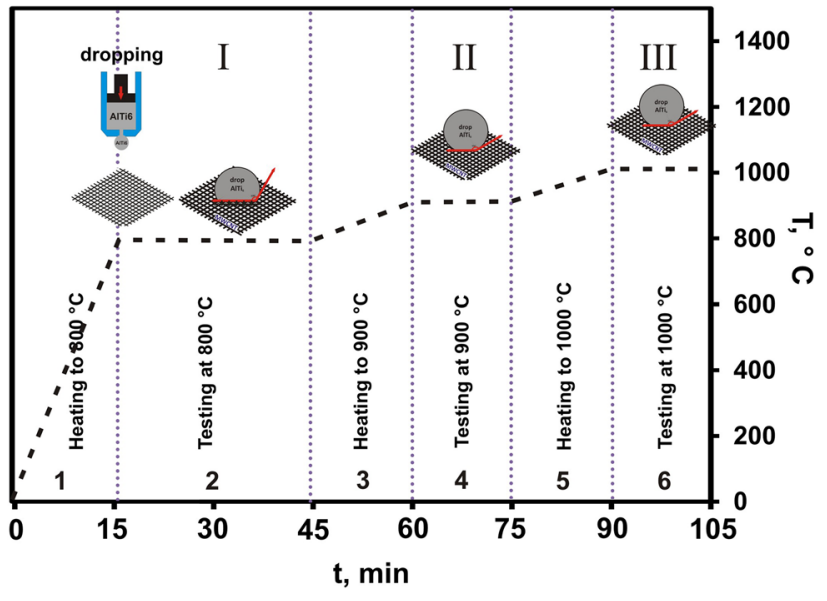

Fig. 1 Temperature profile of the wettability tests: (1) heating to a temperature of $800{ }^{\circ} \mathrm{C}$ with a rate of $5{ }^{\circ} \mathrm{C} / \mathrm{min}$; (2) drop squeezing onto the MWCNT substrate and holding for $30 \mathrm{~min}$ at $800{ }^{\circ} \mathrm{C}$ (Stage I); (3) heating to $900{ }^{\circ} \mathrm{C}\left(5^{\circ} \mathrm{C} / \mathrm{min}\right)$; (4) holding for $15 \mathrm{~min}$ at $900{ }^{\circ} \mathrm{C}$ (Stage II); (5) heating to $1000{ }^{\circ} \mathrm{C}\left(5^{\circ} \mathrm{C} / \mathrm{min}\right)$; and (6) holding for $15 \mathrm{~min}$ at $1000{ }^{\circ} \mathrm{C}$ (Stage III)

\section{Results}

Prior to the wettability studies, the substrate of the asreceived MWCNT paper was subjected to microscopic examinations with LM, SEM/EDS, and HRTEM/EDS. Top-view surface observations by SEM (Fig. 2a and b) and LM (Fig. 2c) show its dense structure, free from any cracks and discontinuities. The surface of MWCNT paper shows the presence of well-ordered hexagonal areas whose average diameter reaches $450 \mu \mathrm{m}$ and height is in the range of $50-53 \mu \mathrm{m}$ (Fig. 2c). The entire surface of the MWCNT paper is covered with small oval precipitates (Fig. 2a and b).

TEM of cross-sectioned MWCNT paper (Fig. 3) indicates that the examined substrate is composed of entangled nanotubes (Fig. 2a and b). Occasionally, the presence of amorphous carbon phase (Fig. 3a) and nanopores (Fig. 3b) is also observed.

The detailed structural characterization of cross-sectioned MWCNTs by means of high-resolution transmission electron microscopy (HRTEM) proved that they contain multi-walled structure with an average wall thickness of 12-80 nm, distance between the carbon layers of $\sim 0.33 \mathrm{~nm}$, and the average number of layers is in the range of 40-200 (Fig. 3c). Occasionally, the presence of foreign particles in the form of iron nano-crystallites was also detected (Fig. 3d and 4a and b). Most probably, they were formed during the production of MWCNT and present residual iron. It should be highlighted that iron has high catalytic activity for the decomposition of carbon compounds and, therefore, it is widely used as a catalyst material for synthesis of MWCNTs. However, as reported in Ref 32, its complete removal is almost impossible.

Figure 5 shows the change of contact angle $(\theta)$ with time and temperature of wettability test of the AlTi6/MWCNT couple. Immediately after squeezing through a ceramic capillary and deposition on MWCNT substrate at a temperature of $800{ }^{\circ} \mathrm{C}$, the AlTi6 drop does not wet the substrate $(\theta>90)$ forming a high contact angle of $153^{\circ}$ (Fig. 5a). Holding the system for $30 \mathrm{~min}$ at $800{ }^{\circ} \mathrm{C}$ as well as next heating to and at

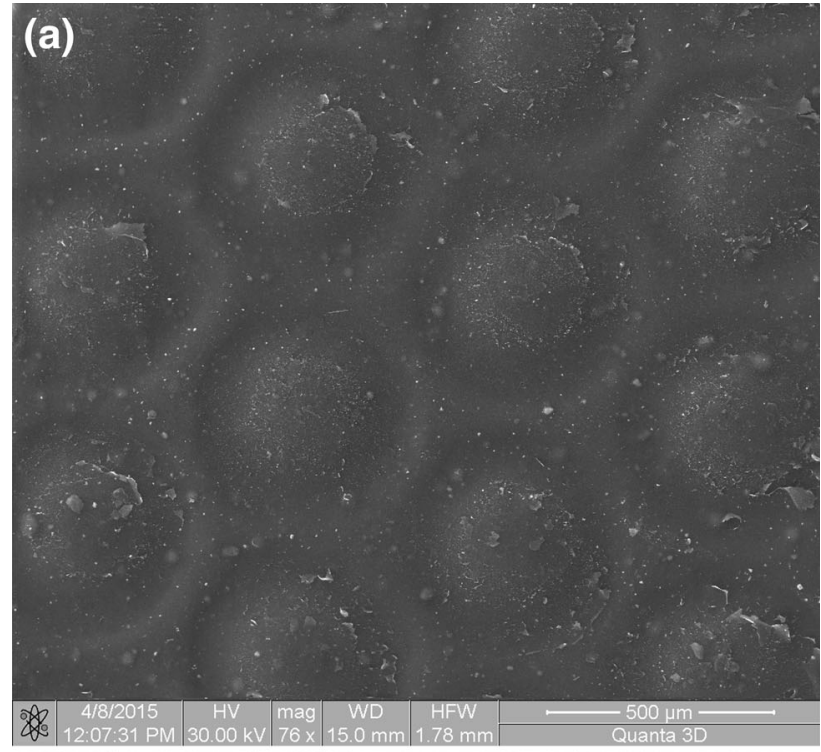

(b)
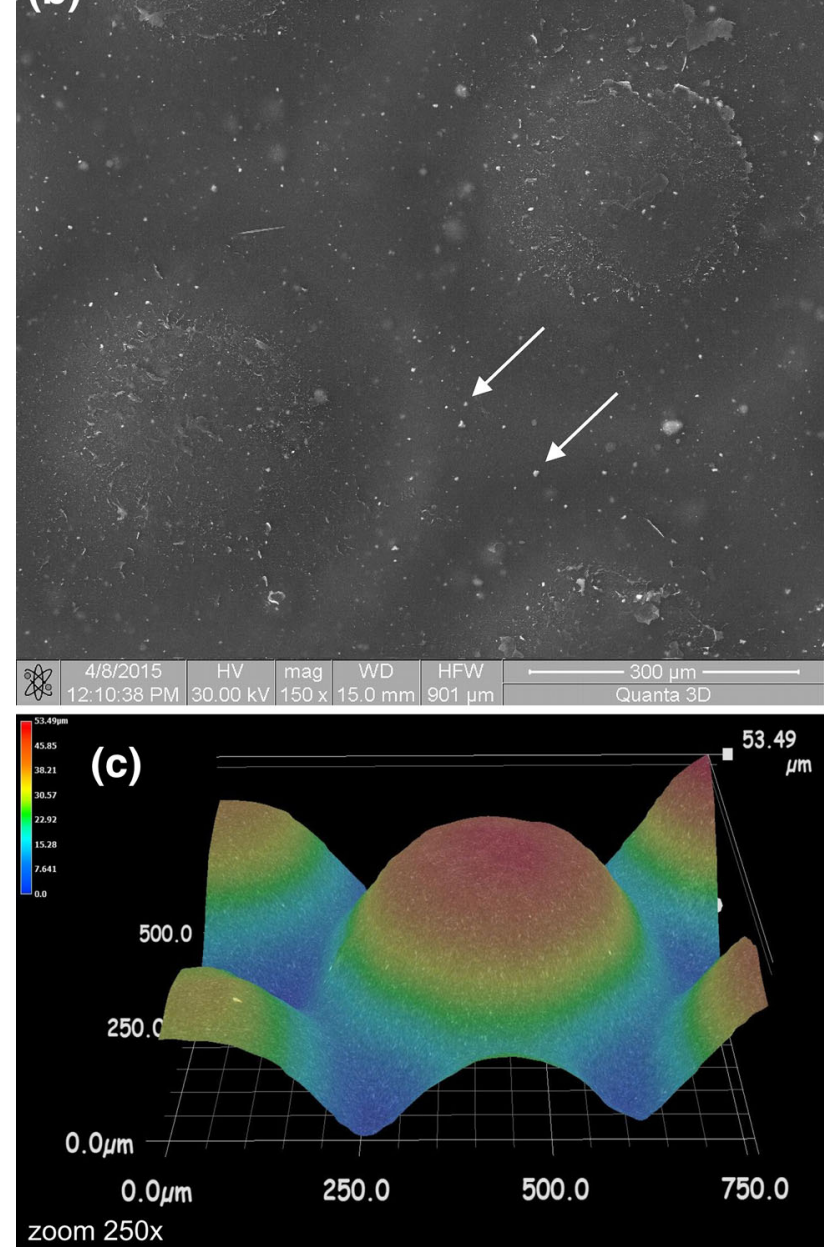

Fig. 2 (a, b) Top-view SEM images of MWCNT paper surface under different magnifications showing well-ordered hexagonal areas (a) and small oval precipitates (b); (c) 3D-LM image showing the topography of MWCNT paper surface

$900{ }^{\circ} \mathrm{C}$ for $15 \mathrm{~min}$ does not affect the value of the contact angle. However, above $930{ }^{\circ} \mathrm{C}$ (Fig. 5b), further increase in temperature (rate of $5{ }^{\circ} \mathrm{C} / \mathrm{min}$ ) causes a gradual lowering of the 


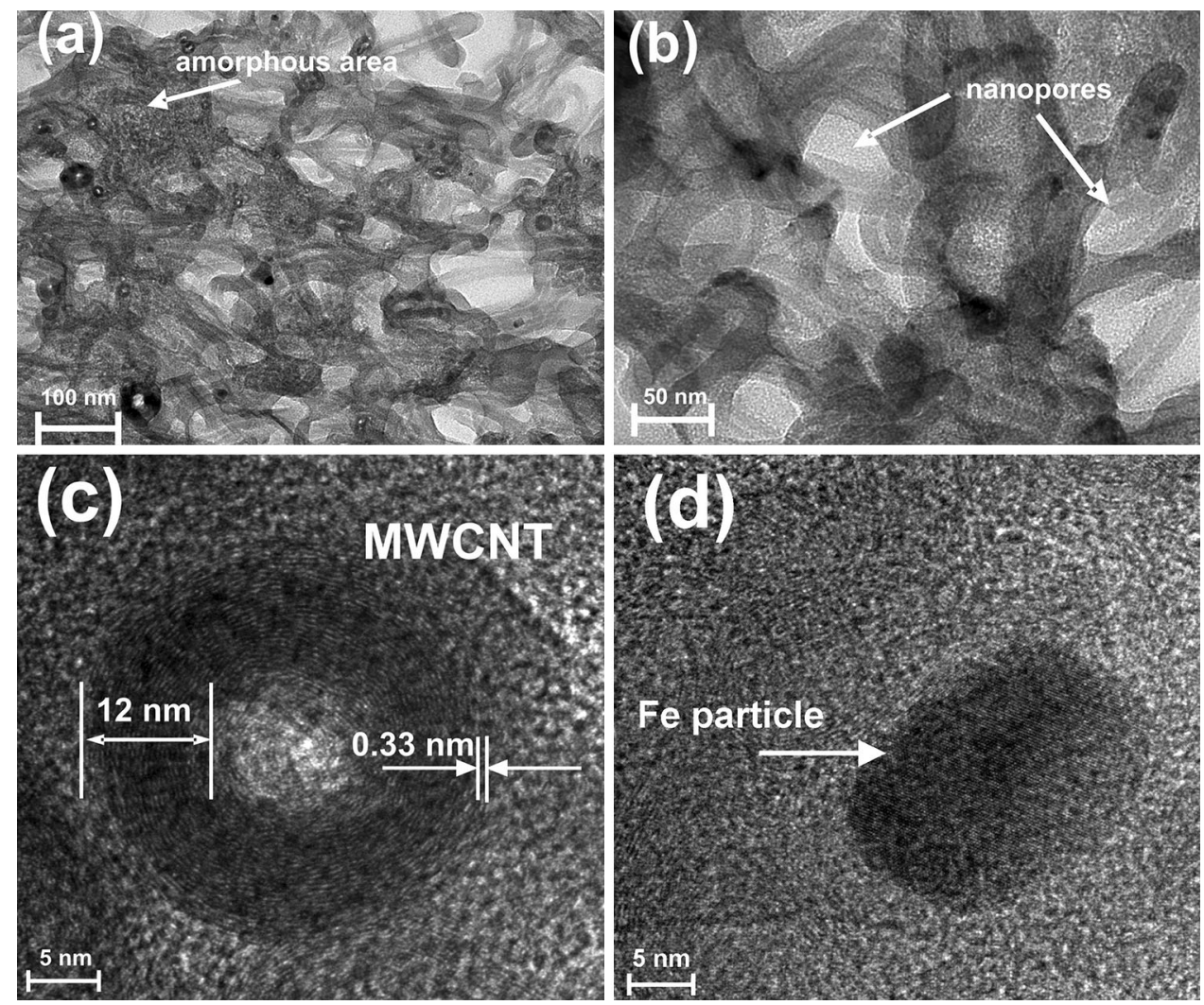

Fig. 3 (a, b) TEM (BF) images of cross-sectioned MWCNT paper substrate showing the presence of amorphous carbon phase (a) and nanometer-sized pores between nanotubes (b); (c, d) HRTEM images showing the inner structure of MWCNT (c) and Fe particle (d)
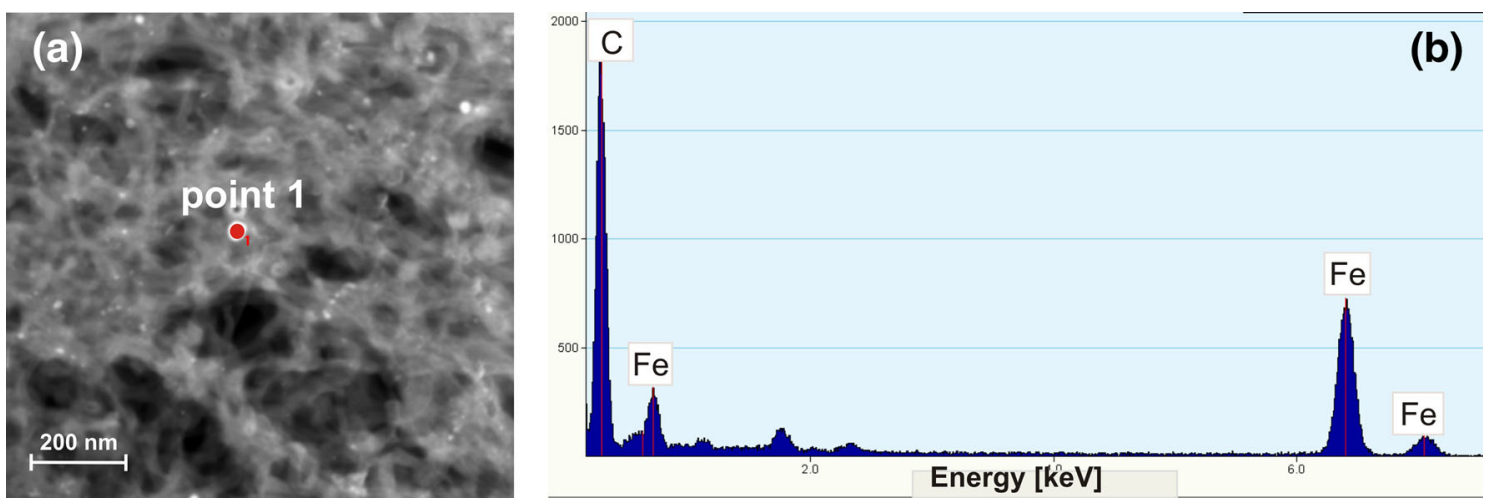

Fig. 4 (a) HAADF-STEM image of MWCNT paper and (b) EDS spectra from point 1 marked in (a)

contact angle to the value of about 130 at $1000{ }^{\circ} \mathrm{C}$. The contact angle continues to decrease during holding at that temperature and finally it stabilizes at $123^{\circ}$ after about 10 -min interaction.

It should be highlighted that the first two trials performed with the AlTi6 alloy on MWCNT substrates evidenced some problems because the AlTi6 drop "disappeared" during its deposition, i.e., immediately after its squeezing from the capillary. Such drop behavior can be related with fast liquid metal infiltration inside MWCNT paper. Our previous results with the AlTi6 alloy on bulk carbon substrates (graphite, glassy-like carbon (Ref 20,21)) as well as carbon-coated alumina substrates (Ref 22) under the same testing conditions showed fast and good wetting. Contrary to previous results, structural characterization of the substrate after the above trials in this study did not show any residual metal on the examined surface of the MWCNT substrate. Moreover, the detailed analysis of images collected in subsecond time of these tests (Fig. 6a-f) just after squeezing the metal at $800{ }^{\circ} \mathrm{C}$ from $\sim 10 \mathrm{~mm}$ height revealed that the falling AlTi6 drop only touched the MWCNT substrate and immediately jumped up. This process repeated a few times and it was accompanied with drop movement to the edge of the substrate and falls off the substrate. Such drop behavior suggests very weak adhesion of 

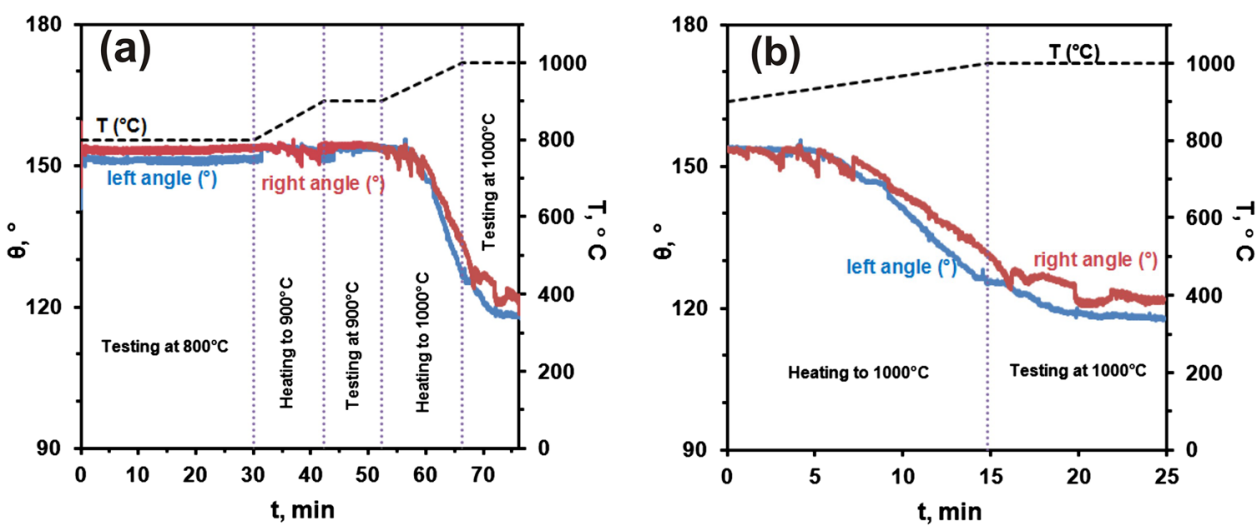

Fig. 5 Wettability kinetics of molten AlTi6 on MWCNT paper at different temperatures: (a) 800-1000 ${ }^{\circ} \mathrm{C}$; (b) the magnified part of (a) for 900 $1000{ }^{\circ} \mathrm{C}$
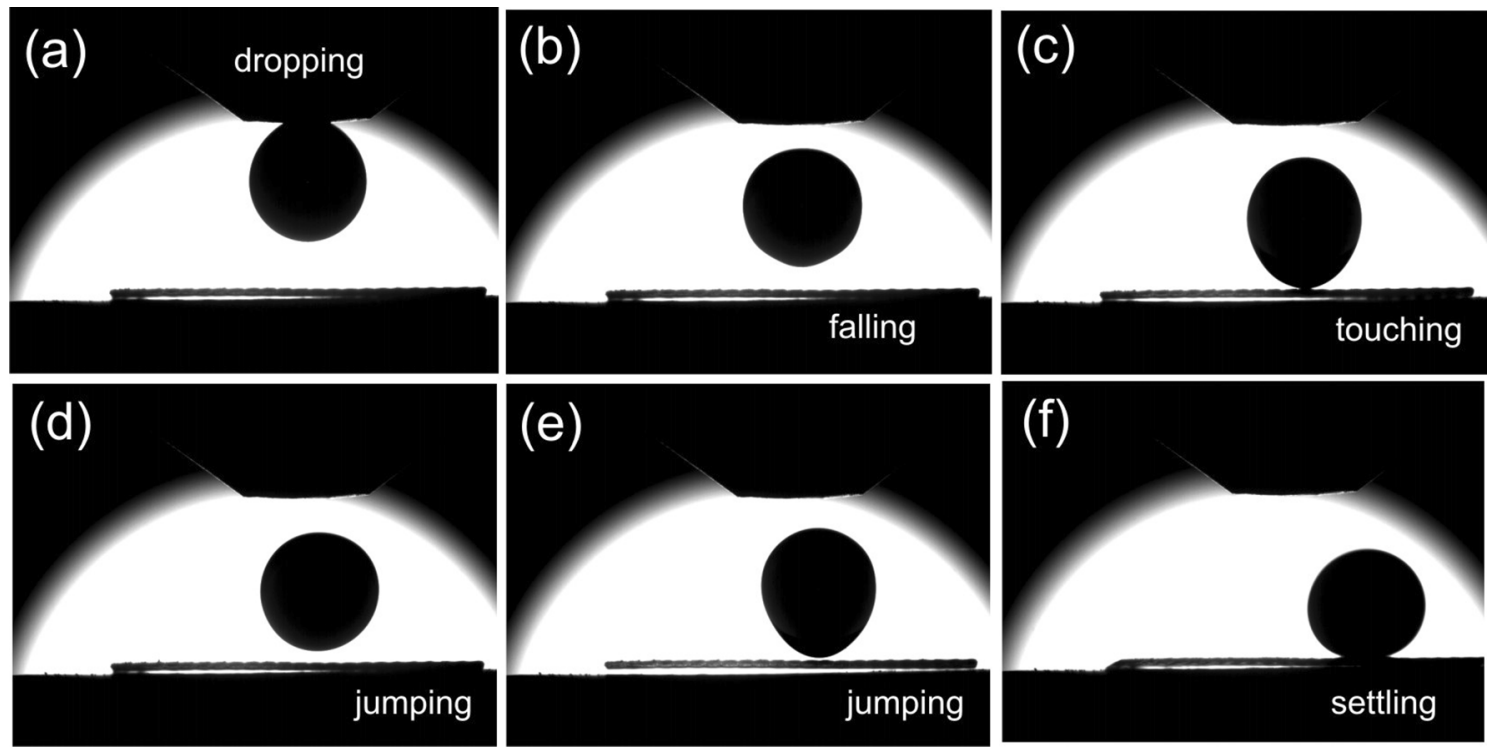

Fig. 6 Images of falling AlTi6 drop recorded with the high-speed high-resolution camera during most representative moments of the beginning of $800{ }^{\circ} \mathrm{C}$ test: (a) metal dropping from the capillary at a height of $5 \mathrm{~mm}$; (b) drop falling on MWCNT substrate; (c) drop touching MWCNT substrate; (d-e) drop jumping; and (g) drop settling on MWCNT substrate after 4th jumping

the AlTi6 drop to the MWCNT substrate, thus opposing to graphite, glassy-like carbon, and alumina substrates coated with graphite, soot, and PVD carbon (Ref 22).

In order to overcome the problem of weak adhesion that contributes to the drop movement along the substrate, the distance between the capillary and the substrate in the next test was decreased up to $5 \mathrm{~mm}$. For this test, four drop jumps were recorded but with only small drop displacement along the substrate. Consequently, the drop settled without spreading (Fig. 6f). Raising the temperature by $100{ }^{\circ} \mathrm{C}$ did not affect the drop shape and position (Fig. 7a and b), while further increase in temperature and time of interaction caused the change in drop shape due to slight improvement in wetting (Fig. 7c-f).

Visual observations of the solidified sessile drop AlTi6/ MWCNT couple showed that the MWCNT substrate has changed its color in the vicinity of the AlTi6 drop from dark black to glossy light gray, marked by arrow in Fig. 8 .
TEM examination of MWCNT substrate under the drop of the cross-sectioned AlTi6/MWCNT sample revealed that it presents heterogeneous structure of metal matrix composite composed of numerous rod-like crystallites and fine particles uniformly distributed in the metal matrix (Fig. 9a and b). The crystallites have a square base (Fig. 9c) with a diagonal of up to $180 \mathrm{~nm}$ and of different lengths that occasionally reach the value of $1 \mu \mathrm{m}$ (Fig. 9d-f). The inspected area was free of unreacted carbon nanotubes or their fragments, while examined rod-like crystallites were dense and free of voids and cracks. There was only one rod-like crystallite with a void located inside at the end of the rod (Fig. 10).

The larger rod-like crystallites frequently show the presence of planar defect along their long axis (Fig. 9c and e) as well as a local thinning-out in the form of windows (Fig. 9d and $\mathrm{f}$ and 10 ), what may arise as the kink and ledge growth mechanism is in operation. 


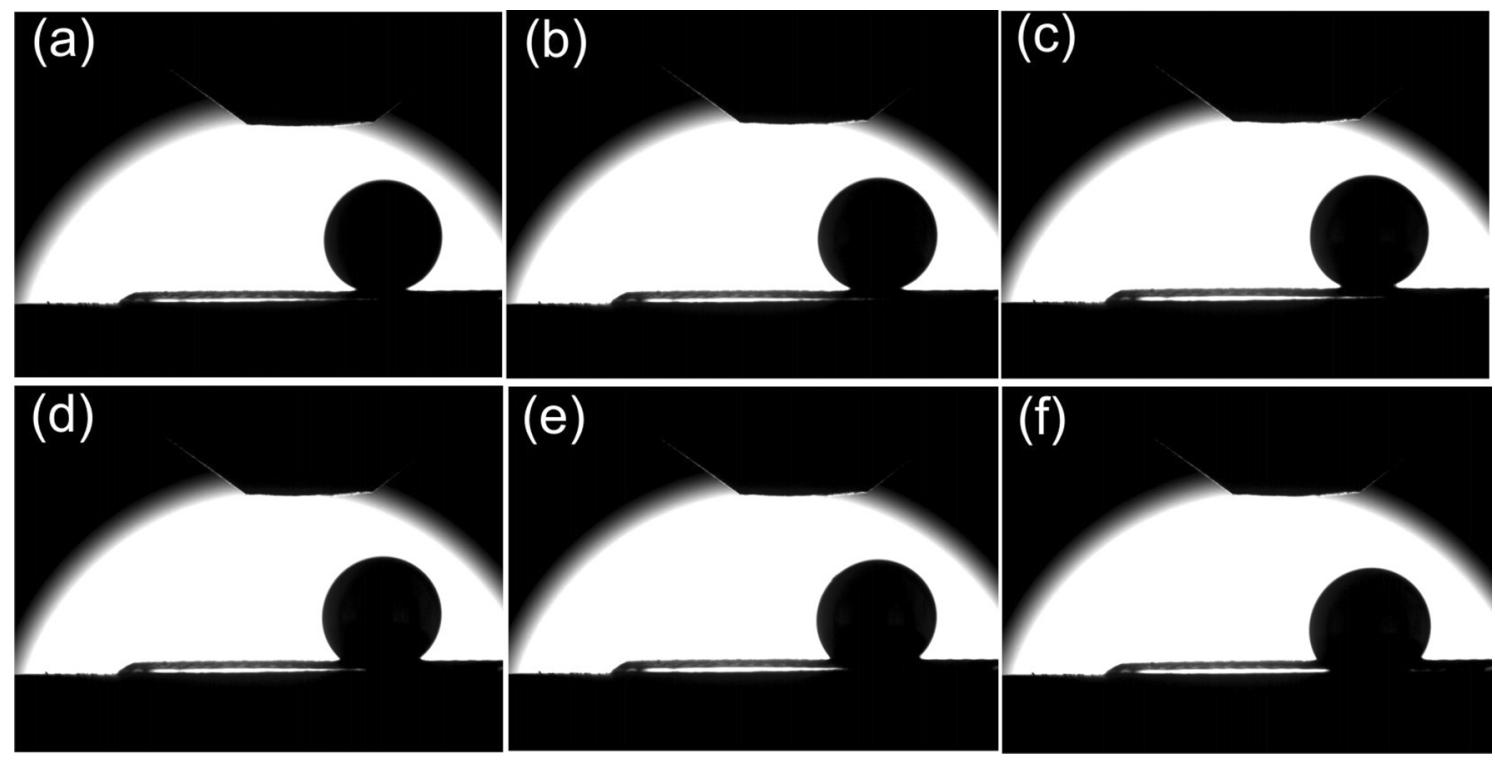

Fig. 7 Images showing the effect of temperature on the shape of TiAl6 drop: (a) after 30 min at $800{ }^{\circ} \mathrm{C}$; (b) after 15 min at $900{ }^{\circ} \mathrm{C}$; (c) after 6-min heating to $1000{ }^{\circ} \mathrm{C}$; (d) after 12 -min heating to $1000{ }^{\circ} \mathrm{C}$; (e) at $1000{ }^{\circ} \mathrm{C}, t=0 \mathrm{~min}$; and (f) after 12 min at $1000{ }^{\circ} \mathrm{C}$

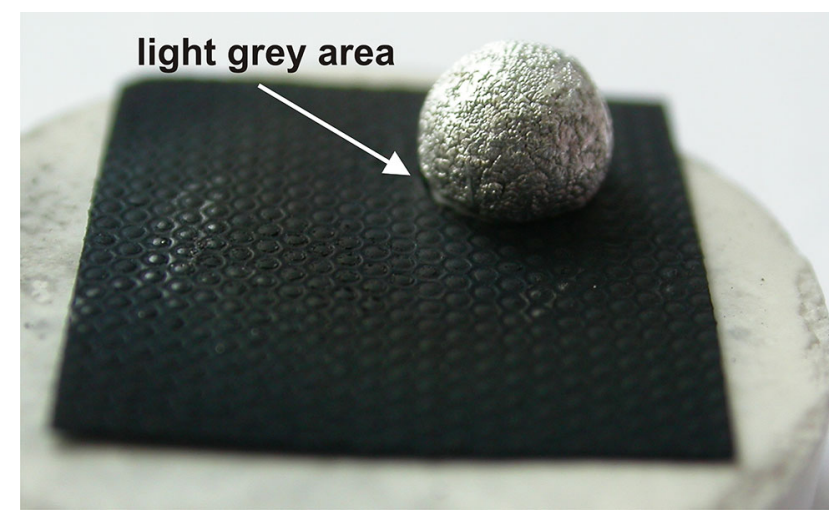

Fig. 8 Photos of solidified sessile drop AlTi6/MWCNT sample; an arrow marks light gray area in the vicinity of AlTi6 drop

The analysis of distribution of elements (Ti, Al, C, Fe) in the metal-infiltrated region and the chemical composition in selected phases shown in Fig. 11(a) has revealed that both the larger rod-like and smaller rounded crystallites composed of titanium and carbon surrounded with practically pure aluminum metal matrix (Fig. 11b and c). Occasionally, the presence of residual iron was also identified (Fig. 11b and c, point 3). Transmission electron microscopy (Fig. 12) and the selected area diffraction patterns taken from the single rod-like crystallite indicate cubic structure of $\mathrm{TiC}$ phase.

\section{Discussion}

The results of wettability tests of the AlTi6/MWCNT couple are summarized in Table 1 and compared with previous studies on wetting properties of AlTi6 alloy in contact with different types of graphite having a similar porosity of about 18\% (Ref
20), glassy-like carbon (Ref 21), and alumina substrates coated with different carbon layers (Ref 22).

Near melting point, pure liquid $\mathrm{Al}$ does not wet either graphite $\left(C_{\mathrm{gr}}\right)$ or glassy-like carbon $\left(C_{\mathrm{glc}}\right)$ showing a high contact angle of $130-160^{\circ}$, depending on carbon material and testing technique, i.e., $150-160^{\circ}$ for $\mathrm{SD} / \mathrm{ch}$ technique (oxidized $\mathrm{Al}$ ) and $130-140^{\circ}$ for $\mathrm{SD} / \mathrm{cp}$ technique (unreacted $\mathrm{Al}$ on carbon substrate) (Ref 23). The Al drop free of oxide film wets carbon substrates at a temperature of $880^{\circ} \mathrm{C}$ forming a contact angle of $50-70^{\circ}$ (Ref 24,25$)$. This wetting has a reactive character, while its mechanism is related to the formation of continuous wettable reaction product $\mathrm{Al}_{4} \mathrm{C}_{3}$. Landry et al. (Ref 23) reported that alloying $\mathrm{Al}$ with $\mathrm{Ti}$ in the amounts compatible with solubility of $\mathrm{Ti}$ in molten aluminum changes neither the spreading kinetics nor the final contact angle on vitreous carbon substrates and the formation of both $\mathrm{TiC}$ and $\mathrm{Al}_{4} \mathrm{C}_{3}$ takes place. On the contrary, our studies (Ref 20,21) evidenced a significant wetting improvement along with the suppression of the formation of $\mathrm{Al}_{4} \mathrm{C}_{3}$ by alloying $\mathrm{Al}$ with high Ti content of 610 wt.\%. Positive effect of high $\mathrm{Ti}$ addition on wetting is particularly well pronounced when carbon is used as a thin coating on the alumina substrate (Ref 22): the AlTi6 alloy does not wet alumina $(\theta=103)$, while on carbon-coated substrates it spreads very fast to form a contact angle of $17-52^{\circ}$, depending on the type of carbon deposited (Table 1).

Compared to glassy-like carbon and different types of graphite, wetting behavior of the AlTi6 alloy on MWCNT paper observed in this study seems to be unusual. While high contact angle in AlTi6/MWCNT couple at $1000{ }^{\circ} \mathrm{C}$ might be associated with wetting hysteresis (i.e., the formation of apparently high contact angle value due to substrate surface roughness and porosity), so far the drop jumping should be affected by another reason. In order to clarify this phenomenon, the analysis of real-time records of residual gases during wettability tests was performed (Fig. 13). It was noted that just before heating when corresponding vacuum of $p=2.34 \times 10^{-6}$ mbar was reached, the amounts of $\mathrm{H}_{2} \mathrm{O}$ and $\mathrm{H}_{2}$ recorded in the chamber were comparable to those obtained with other carbon 

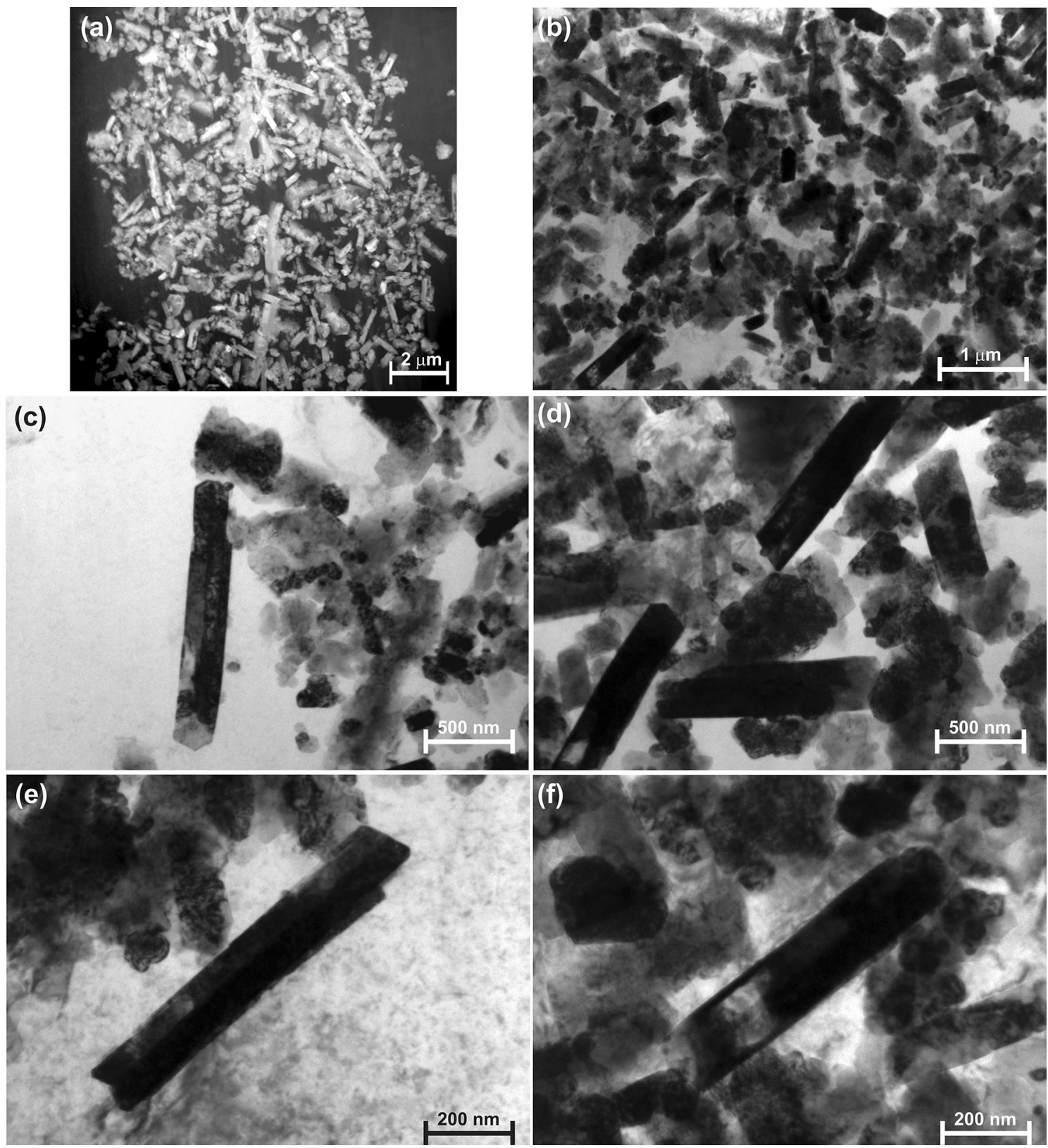

Fig. 9 TEM images of metal-infiltrated region under AlTi6 drop in the AlTi6/MWCNT sessile drop couple under different magnifications showing rod-like crystallites and fine particles uniformly distributed in metal matrix: (a) STEM image of the AlTi6-MWCNT composite and (b-f) BF images of the rod-like crystallites

substrates or carbon-coated alumina (Fig. 13a). However, increase in temperature caused much higher gasification from the MWCNT substrate, mainly due to the release of $\mathrm{CO}_{2}, \mathrm{CO}$, $\mathrm{C}, \mathrm{H}_{2} \mathrm{O}$, and $\mathrm{H}_{2}$, particularly noticeable at $200{ }^{\circ} \mathrm{C}$ (Fig. 13b). Despite some decrease in gasification with time and increase in temperature, at the moment of squeezing the drop from the capillary, the pressure of $p=1.45 \times 10^{-5}$ mbar (Fig. 13c) was recorded and it is higher than that usually observed with other carbon materials. Thus, we suggest that the gas release from the MWCNT paper contributed to jumping of the AlTi6 drop and its apparently non-wetting behavior on the MWCNT substrate.

Another reason behind such unusual drop behavior is related to (1) heterogeneous structure of the surface of MWCNT substrate similar to that of lotus leaves like resulting in discontinuous drop/substrate contact and wetting hysteresis effect and (2) periodic deformation of thin MWCNT substrate as it is well documented on the movie of the tests performed (see Supplementary Video 1).

Moreover, non-wetting behavior of the AlTi6 drop/ MWCNT couple and high values of contact angles measured in this study are apparent since liquid metal infiltration took place through the whole thickness of MWCNT substrate. This phenomenon can be explained by rather non-wetting of alumina support by the AlTi6 alloy forming at the test temperature the contact angle of 103 (Table 1). The detailed analysis of the sessile drop images (e.g., Fig. 6 and 7) evidenced that liquid metal penetration through MWCNT substrate is accompanied with substrate raising in a way that the liquid drop does not sit 


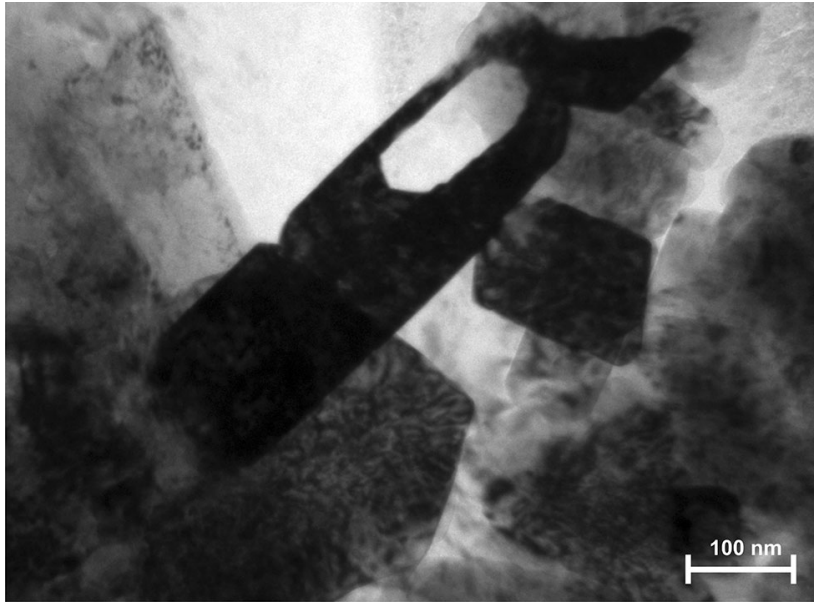

Fig. 10 TEM (BF) image of the single rod-like crystallite with a void inside crystal on the MWCNT substrate anymore and it contacts the alumina support directly.

Besides dissimilar wetting behavior, there is also dissimilar interface structure in the AlTi6/MWCNT couple, compared to other AlTi6/C systems reported in Ref 4, 20-22, 26, 27. Contrary to $\mathrm{AlTi6} / \mathrm{C}_{\mathrm{gr}}$, $\mathrm{AlTi6} / \mathrm{C}_{\text {glc }}$, and $\mathrm{AlTi6} / \mathrm{CF}$ produced under similar time-temperature conditions and using the same experimental device and testing procedures, SEM and TEM analysis of the AlTi6/MWCNT couple did not evidence the presence of $\mathrm{Al}_{4} \mathrm{C}_{3}$ either on the surface of other precipitates or as separate particles in the metallic matrix as it took place with glassy-like carbon (Ref 4) and graphite (Ref 26, 27). Moreover, contrary to previous studies on the interaction of AlTi6 alloy with graphites and glassy-like carbon, showing the formation of very fine $\mathrm{TiC}$ precipitates, reactively formed $\mathrm{TiC}$ particles with MWCNTs in this study are of two morphologies, depending on the carbon source. It can be concluded that the interaction between carbon and $\mathrm{Ti}$ dissolved in molten alloy takes place both with MWCNTs and amorphous carbon formed from
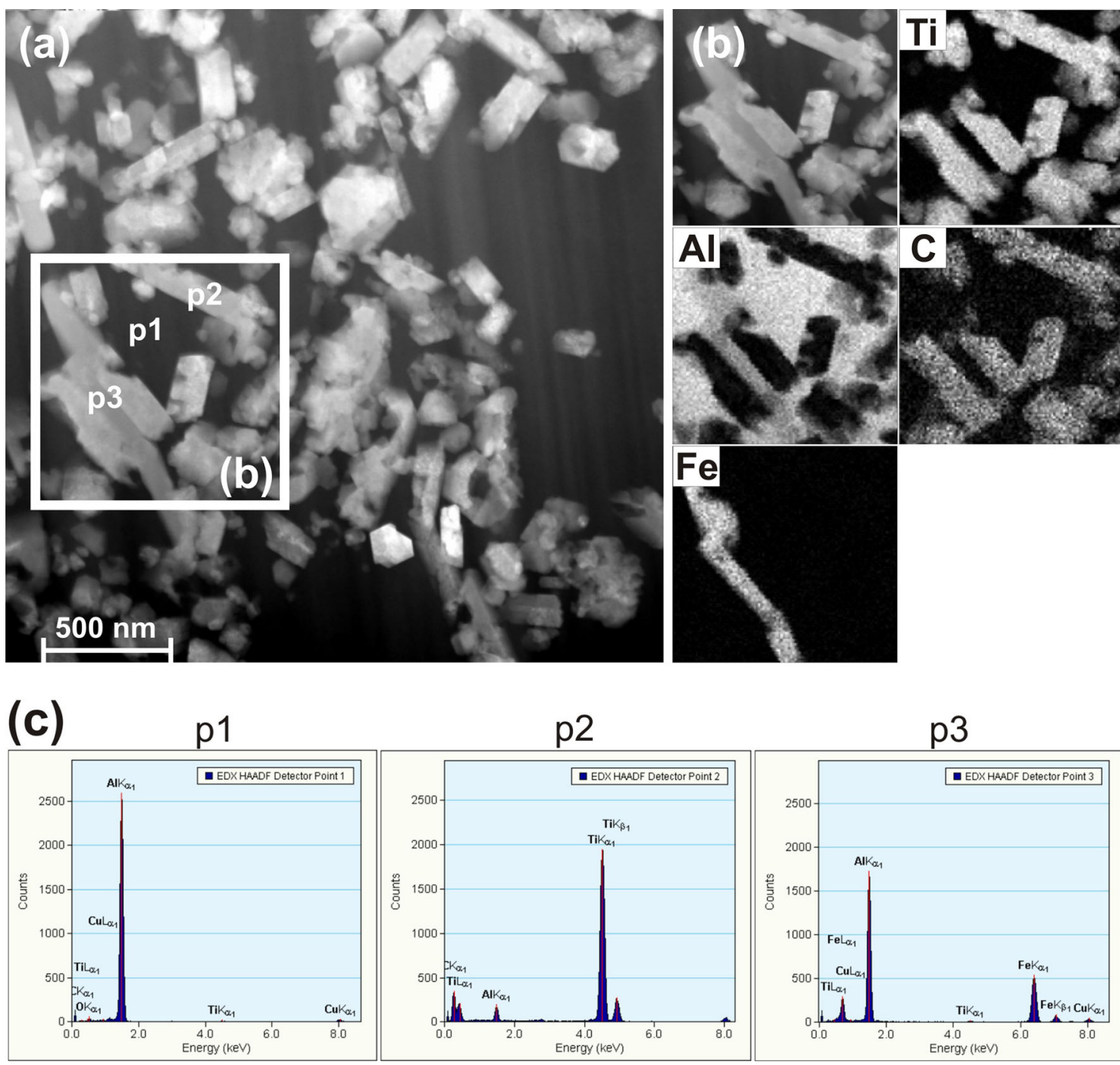

\section{p2}
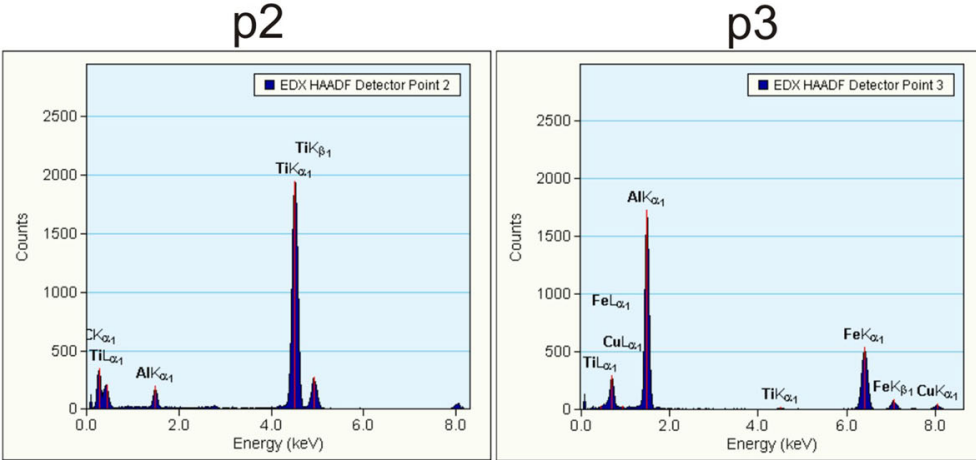

Fig. 11 (a) STEM image of the AlTi6-MWCNT composite; (b) distribution of Ti, Al, C, and Fe in marked area in (a); and (c) EDS spectra taken from points $1-3$ in (a) 


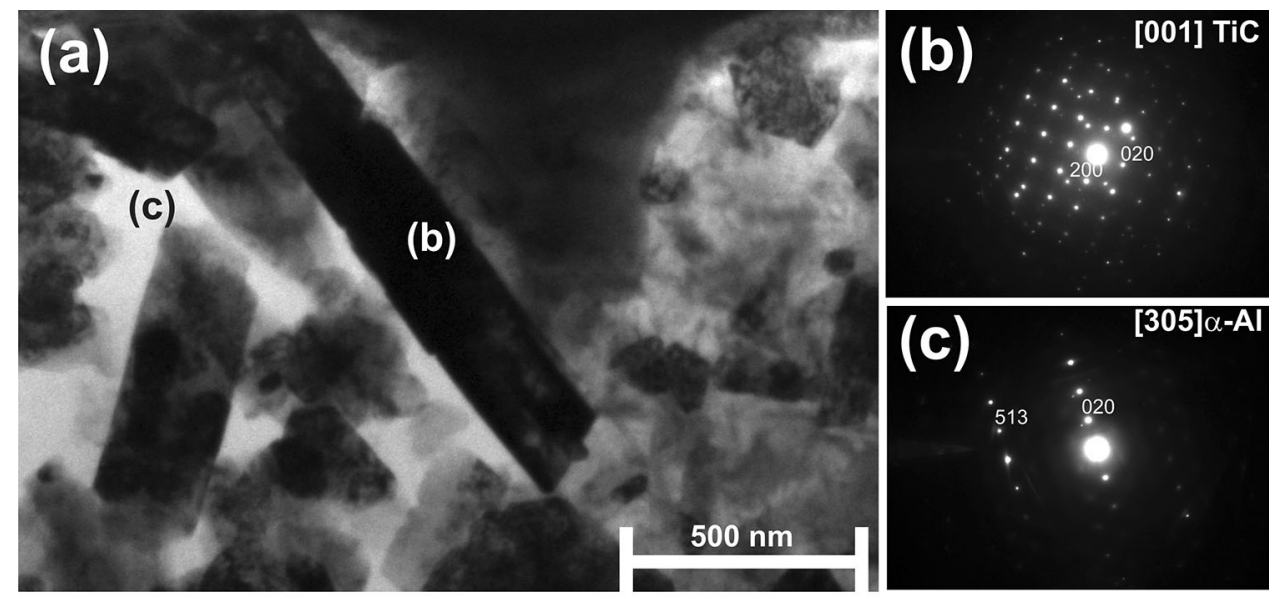

Fig. 12 TEM (BF) image of AlTi6-MWCNT composite showing single rod-like TiC crystallite in metal matrix (a) with corresponding selected area diffraction patterns taken from $\mathrm{TiC}(\mathrm{b})$ and metal matrix (c)

Table 1 Effect of the type of carbon substrate and testing conditions on the contact angle values formed by the AlTi6 alloy on different substrates: SD—sessile drop method; cp-capillary purification technique combined with non-contact heating; ch-contact heating; $\mathrm{C}_{\text {glc }}$-glassy-like carbon; $\mathrm{C}_{\mathrm{gr}}-$ graphite; $\mathrm{C}_{\mathrm{gr}} / \mathrm{Al}_{2} \mathrm{O}_{3}, \mathrm{C}_{\mathrm{PVD}} / \mathrm{Al}_{2} \mathrm{O}_{3}, \mathrm{C}_{\mathrm{s}} / \mathrm{Al}_{2} \mathrm{O}_{3}-$ different carbon coatings on $\mathrm{Al}_{2} \mathrm{O}_{3}$ substrates $\left(\mathrm{C}_{\mathrm{gr}}\right.$ - graphite; $\mathrm{C}_{\mathrm{PVD}}$ - carbon deposited by PVD technique; $\mathrm{C}_{\mathrm{s}}-$ soot)

\begin{tabular}{|c|c|c|c|}
\hline Substrate & Testing conditions & 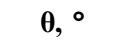 & Ref \\
\hline \multirow[t]{4}{*}{ AlTi6/MWCNT } & $\mathrm{SD} / \mathrm{cp}$, vac. of $1.45-1.21 \times 10^{-5} \mathrm{mbar}, 800^{\circ} \mathrm{C}, 15 \mathrm{~min}$ & 153 & This work \\
\hline & $\mathrm{SD} / \mathrm{cp}$, vac. of $1.64-1.87 \times 10^{-5} \mathrm{mbar}, 900{ }^{\circ} \mathrm{C}, 15 \mathrm{~min}$ & 154 & \\
\hline & $\mathrm{SD} / \mathrm{cp}$, vac. of $2.03-1.61 \times 10^{-5} \mathrm{mbar}, 930^{\circ} \mathrm{C}, 5 \mathrm{~min}$ & 154 & \\
\hline & $\mathrm{SD} / \mathrm{cp}$, vac. of $2.03-1.61 \times 10^{-5} \mathrm{mbar}, 1000^{\circ} \mathrm{C}, 15 \mathrm{~min}$ & 123 & \\
\hline \multirow{4}{*}{$\mathrm{AlTi6} / \mathrm{C}_{\mathrm{gr}}$} & $\mathrm{SD} / \mathrm{cp}$, vac. of $1.0 \times 10^{-5} \mathrm{mbar}, 850{ }^{\circ} \mathrm{C}, 30 \mathrm{~min}$ & $148-146$ & Ref 20 \\
\hline & $\mathrm{SD} / \mathrm{cp}$, vac. of $1.0 \times 10^{-5} \mathrm{mbar}, 950^{\circ} \mathrm{C}, 30 \mathrm{~min}$ & $98-56$ & \\
\hline & $\mathrm{SD} / \mathrm{cp}$, vac. of $1.0 \times 10^{-5} \mathrm{mbar}, 1050^{\circ} \mathrm{C}, 30 \mathrm{~min}$ & $20-7$ & \\
\hline & $\mathrm{SD} / \mathrm{cp}$, vac. of $1.0 \times 10^{-5} \mathrm{mbar}, 1150^{\circ} \mathrm{C}, 15 \mathrm{~min}$ & 12 & \\
\hline $\mathrm{Al} / \mathrm{C}_{\mathrm{glc}}$ & $\mathrm{SD} / \mathrm{cp}$, vac. $850{ }^{\circ} \mathrm{C}$ & 65 & Ref 21 \\
\hline $\mathrm{AlTi6} / \mathrm{C}_{\mathrm{glc}}$ & $\mathrm{SD} / \mathrm{cp}$, vac. $850{ }^{\circ} \mathrm{C}$ & 60 & \\
\hline $\mathrm{AlTi6} / \mathrm{C}_{\mathrm{glc}}$ & $\mathrm{SD} / \mathrm{ch}, \mathrm{vac}, 950-1050{ }^{\circ} \mathrm{C}$ & $78-15$ & \\
\hline AlTi6/ $\mathrm{Al}_{2} \mathrm{O}_{3}$ & $\mathrm{SD} / \mathrm{ch}$, vac. $1.0 \times 10^{-6} \mathrm{mbar}, 1000^{\circ} \mathrm{C}, 120 \mathrm{~min}$ & 103 & Ref 22 \\
\hline $\mathrm{AlTi} 6 / \mathrm{C}_{\mathrm{gr}} / \mathrm{Al}_{2} \mathrm{O}_{3}$ & $\mathrm{SD} / \mathrm{ch}$, vac. $1.0 \times 10^{-6} \mathrm{mbar}, 1000^{\circ} \mathrm{C}, 30 \mathrm{~min}$ & 52 & \\
\hline $\mathrm{AlTi} / \mathrm{C}_{\mathrm{s}} / \mathrm{Al}_{2} \mathrm{O}_{3}$ & $\mathrm{SD} / \mathrm{ch}$, vac. $1.0 \times 10^{-6} \mathrm{mbar}, 1000^{\circ} \mathrm{C}, 30 \mathrm{~min}$ & 17 & \\
\hline $\mathrm{AlTi} / \mathrm{C}_{\mathrm{PVD}} / \mathrm{Al}_{2} \mathrm{O}_{3}$ & $\mathrm{SD} / \mathrm{ch}$, vac. $1.0 \times 10^{-6} \mathrm{mbar}, 1000^{\circ} \mathrm{C}, 30 \mathrm{~min}$ & 18 & \\
\hline
\end{tabular}

organic binder during the production of MWCNT paper. It results in the formation of rod-like crystallites and fine particles, respectively. Similar fine $\mathrm{TiC}$ particles were observed previously after the interaction of $\mathrm{Al}-\mathrm{Ti}$ and $\mathrm{Cu}-\mathrm{Ti}$ alloys with glassy-like carbon (Ref 4, 21-23) and graphite (Ref 20). The formation of nanorod-like $\mathrm{TiC}$ crystallites was reported in Al20Ti/MWCNT system (Ref 33).

It should be highlighted that also different type and morphology of carbide phase reactively formed in Al-matrix composites reinforced with CNTs have been reported in the literature. Most studies conducted with pure $\mathrm{Al}$ evidenced the $\mathrm{Al}_{4} \mathrm{C}_{3}$ nanotubes formed by the template-type mechanism $(\operatorname{Ref} 8,10))$. Kwon et al. (Ref 10) observed the tube-shaped $\mathrm{Al}_{4} \mathrm{C}_{3}$ generated on the surface of defective CNTs, whereas particle-shaped $\mathrm{Al}_{4} \mathrm{C}_{3}$ was generated on the tips of CNTs. In this case, Al-CNTs composite was fabricated by means of solid-state processing using SPS of Al-CNTs powder mixture pre-annealed for $2 \mathrm{~h}$ at $500{ }^{\circ} \mathrm{C}$ in $\mathrm{Ar}$ and then sintered at $480-600{ }^{\circ} \mathrm{C}$ under a pressure of $50 \mathrm{MPa}$. In the temperature range $400-950{ }^{\circ} \mathrm{C}$ involving both solid-state and liquid-state processing, $\mathrm{Ci}$ et al. (Ref 8) identified nanosize $\mathrm{Al}_{4} \mathrm{C}_{3}$ formed at the $\mathrm{Al} / \mathrm{CNT}$ interfaces. The results indicated that independently of temperature, the reaction generally occurred at locations containing an amorphous carbon coating, at defect sites, and at open ends of CNTs, while graphitic basal planes of the $\mathrm{CNT}$ walls were inactive toward Al. For a higher temperature of $950{ }^{\circ} \mathrm{C}$, Ci et al. (Ref 8) found catalyst-like growth of $\mathrm{Al}_{4} \mathrm{C}_{3}$ nano-whiskers as well as reactively formed $\mathrm{Al}_{4} \mathrm{C}_{3}$ nanowires using CNTs as templates.

Laha et al. (Ref 9) applied liquid-phase processing through thermal spraying of hypereutectic Al-Si alloy containing MWCNTs. In this process, reactive wetting needed for composite consolidation was accompanied with the formation of ultrathin (nanometer level) continuous layer of $\beta$-SiC on the surface of MWCNTs following the reaction between Si from the alloy and carbon from MWCNTs:

$\mathrm{Si}+\mathrm{C}=\mathrm{SiC}$.

On the contrary, Elshalakany et al. (Ref 11) did not find either $\mathrm{Al}_{4} \mathrm{C}_{3}$ or $\mathrm{SiC}$ in composite produced from $\mathrm{A} 356$ alloy (6 wt.\% $\mathrm{Si}$ ) and 1-2.5 wt.\% MWCNTs by a combined technique of rheocasting and squeeze casting. 

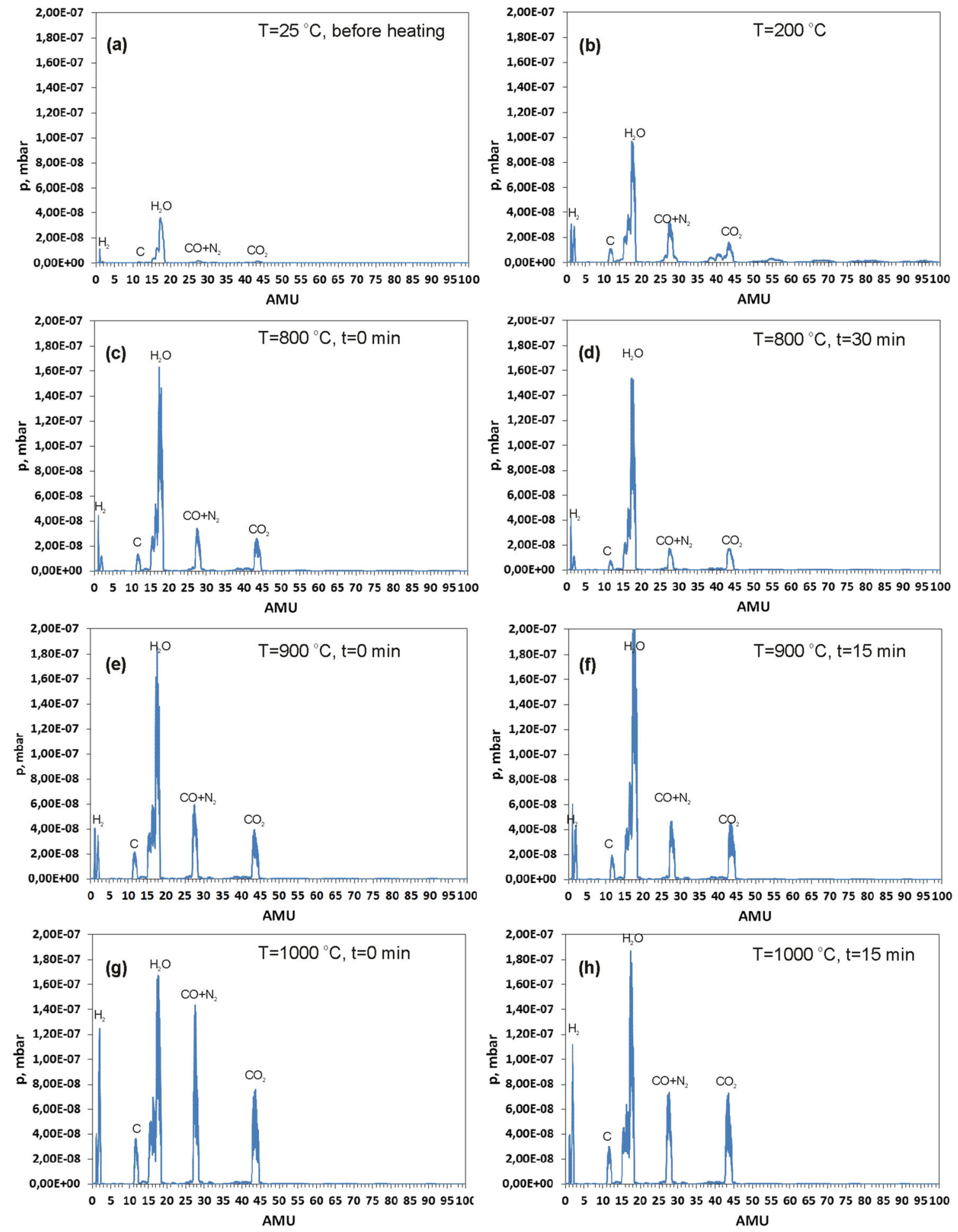

Fig. 13 Partial pressure of residual gases in the test chamber recorded during experiment with AlTi6/MWCNT couple: (a) RT - before heating; (b) $T=200{ }^{\circ} \mathrm{C}$; (c) $T=800{ }^{\circ} \mathrm{C}$ - dropping; (d) $T=800{ }^{\circ} \mathrm{C}, \quad t=30 \mathrm{~min} ; \quad$ (e) $T=900{ }^{\circ} \mathrm{C}, \quad t=15 \mathrm{~min} ; \quad(f) \quad \mathrm{T}=900{ }^{\circ} \mathrm{C}, \quad t=15 \mathrm{~min}$; (g) $T=1000^{\circ} \mathrm{C}, t=0 \mathrm{~min}$; and (h) $T=1000^{\circ} \mathrm{C}, t=15 \min$ (end of the test)

Taking into account that the Gibbs free energies of the formation of $\mathrm{Al}_{4} \mathrm{C}_{3}$ and $\mathrm{TiC}$ at $1000{ }^{\circ} \mathrm{C}$ are -150 and $-169 \mathrm{~kJ} / \mathrm{mol}$, respectively (Ref 34 ), one may conclude that the formation of $\mathrm{TiC}$ is thermodynamically more feasible in the AlTi6/C system. However, due to small differences between the above values, kinetic factors play an important role in the final structure of AlTi6/C couples. It was evidenced experimentally that depending on the location with respect to metal/substrate contact, both $\mathrm{Al}_{4} \mathrm{C}_{3}$ and $\mathrm{TiC}$ can be formed in AlTi6/C couples formed with graphite (Ref 26, 27). This situation is related to the specific nature of AlTi6 alloy that melts over a wide temperature range of $664-1122{ }^{\circ} \mathrm{C}$. At a temperature of 


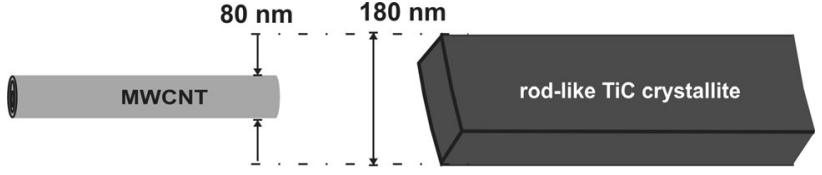

Fig. 14 Comparison of the average size of MWCNTs to that of rod-like TiC crystallites formed in AlTi6/MWCNT couple at $1000{ }^{\circ} \mathrm{C}$

$1000{ }^{\circ} \mathrm{C}$, it still contains some amount of $\mathrm{Al}_{3} \mathrm{Ti}$ phase that presents a source of fresh Ti playing an important role in reactive wetting of ceramic substrates (Ref 35). Therefore, besides the kinetics of chemical reactions between $\mathrm{Al}$, $\mathrm{Ti}$, and $\mathrm{C}$, the kinetics of dissolution of residual $\mathrm{Al}_{3} \mathrm{Ti}$ particles and the kinetics of diffusion of $\mathrm{Ti}$ in molten $\mathrm{Al}$ should be taken into consideration together with the kinetics of liquid metal infiltration into a carbon substrate. In this study, CNT paper of about $0.2 \mathrm{~mm}$ thickness was more than one order of magnitude thinner, compared to $C_{\mathrm{glc}}$ and $C_{\mathrm{gr}}$ substrates in previous reports $(3 \mathrm{~mm}(\operatorname{Ref} 4,21,22)$ and $5 \mathrm{~mm}(\operatorname{Ref} 20,21$, 26, 27), respectively). Consequently, liquid metal penetration took place in a whole MWCNT substrate thickness, whereas whole $\mathrm{Ti}$ from the alloy was consumed for the formation of $\mathrm{TiC}$ without involving $\mathrm{Al}$ in the reaction with $\mathrm{CNT}$.

As a consequence of above considerations, it may be concluded that under conditions of this study, the formation of TiC in AlTi6/MWCNT couple is dominant and it leads to the transformation of MWCNTs of 35-80 nm diameter to dense rod-like crystallites having a maximum size of about $180 \mathrm{~nm}$ (Fig. 14).

This observation is in good agreement with the calculations of relative volume change $\Delta V / V(\%)$ due to phase transformations from carbon phase (molar volume $V_{\mathrm{C}}$ ) to metal carbide $\mathrm{MC}$ (molar volume $V_{\mathrm{MC}}$ ):

$\Delta V / V=\left(V_{\mathrm{MC}}-V_{\mathrm{C}}\right) / V_{C} \times 100 \%$

For reaction (3), the formation of $\mathrm{TiC}$ from graphite $\left(V_{\mathrm{Cgr}}=5.22 \mathrm{~cm}^{3} / \mathrm{mol}\right)$ is accompanied with about $135 \%$ volume expansion, while $\Delta V / V$ is $85 \%$ with glassy-like carbon $\left(V_{\mathrm{Cglc}}=6.67 \mathrm{~cm}^{3} / \mathrm{mol}\right)$ and $32-53 \%$ with MWCNT $\left(V_{\text {MVCNT }}=8-9.23 \mathrm{~cm}^{3} / \mathrm{mol}(\operatorname{Ref} 9)\right)$. Assuming that the TiC phase nucleates and grows at the surface of MWCNTs, subsequently resulting in their complete consumption, such significant volume increase is due to $M W C N T \rightarrow T i C$. Most probably, it may be another reason why SEM and TEM observations do not recognize $\mathrm{TiC}$ nanotubes since growing TiC phase does not duplicate an inner shape of starting CNT reactant.

However, the above considerations differ from the statements of Laha et al. (Ref 9) who using the same approach estimated that the volume of MWCNTs consumed by the reaction (3) is about $40 \%$ less than the volume of reactively formed $\mathrm{SiC}$. Therefore, the authors suggested a complete coverage of the surface of MWCNTs with the SiC layer free of any discontinuities. Since the values of $\Delta V / V$ for both reactions (3) and (4) with MWCNTs are comparable, it cannot be excluded that other factors than those discussed above are also responsible for the formation of rod-like morphology of $\mathrm{TiC}$ phase in the AlTi6/MWCNT couple. Contradiction between the experimental results and prediction using the same $\Delta V / V$ approach is the most pronounced for the growth of $\mathrm{Al}_{4} \mathrm{C}_{3}$ phase from liquid $\mathrm{Al}$ at the surface of a carbon material. Calculations show that the generation of one mole of $\mathrm{Al}_{4} \mathrm{C}_{3}$ $\left(V_{\mathrm{Al} 4 \mathrm{C} 3}=49.56 \mathrm{~cm}^{3} / \mathrm{mol}\right)$ from three moles of $C$, following the reaction (1), is accompanied with $93 \%$ relative volume increase with MWCNT contrary to that of $148 \%$ with glassylike carbon and $216 \%$ with graphite. Despite the fact that for MWCNTs $\Delta V / V$ of $\mathrm{Al}_{4} \mathrm{C}_{3}$ is more than twice higher than that of $\mathrm{SiC}$, in both cases nanotube-like morphology of reactively formed carbide is dominant.

Most literature data on the morphology of $\mathrm{TiC}$ phase reactively formed from CNTs is related to two mechanisms: (1) the VLS (vapor-liquid-solid) employing either volatile metal or non-metal complexes (Ref 36) and (2) the SMS involving molten salts (Ref 37). In both cases, the formation of rod-like TiC crystallites has been reported. Another model of the whisker-like growth of the polycrystalline $\mathrm{TiC}$ nanofibers and nanorods through the solid-solid reaction between carbon from MWCNTs and $\mathrm{TiO}_{2}$ originated from the zirconia solid solution $\mathrm{Zr}(\mathrm{Y}, \mathrm{Ti}) \mathrm{O}_{2}$ heat-treated for $2 \mathrm{~h}$ at $1200{ }^{\circ} \mathrm{C}$ in vacuum has been proposed by Pyda and Morgiel (Ref 38). Compared to the above processes and accompanying mechanisms, an exception to the report by Jin et al. (Ref 33), who applied self-propagation high-temperature synthesis of nano- $\mathrm{TiC}_{x}$ particles using CNTs as a source of carbon in Metal-Ti-CNT powder mixture within the range of 20-50 wt.\% CNTs was noted. They demonstrated that different sizes and shapes of $\mathrm{TiC}_{x}$ can be produced depending on the metal (50-80 wt.\% of $\mathrm{Cu}, \mathrm{Al}, \mathrm{Fe})$ and the amount of CNTs. For the $\mathrm{Cu}-\mathrm{Ti}-\mathrm{CNT}$ and Al-Ti-CNT systems, they are mainly octahedral, while those formed in the Fe-TiCNT system are mainly cubic and sphere like.

It is interesting to note that duplication of initial shape of starting nanotube reinforcement by the growth of two reactively formed phases was reported by Lahri et al. (Ref 39) for Almatrix composite reinforced with 4.23 wt. $\%$ boron nitride nanotubes (BNNTs) produced by powder metallurgy solid-state processing in atmospheric pressure at $650{ }^{\circ} \mathrm{C}$ for up to $2 \mathrm{~h}$. According to the authors, the nucleation and growth of the interfacial thin layer composed of two phases (AlN and $\mathrm{AlB}_{2}$ ) depend on the kinetics of the competitive reactions of their formation. Moreover, the shape, size, and location of reactively formed phases at the interface depend on the mechanism of their growth and on the diffusion of $\mathrm{Al}, \mathrm{B}$, and $\mathrm{N}$ through the $\mathrm{BNNT} / \mathrm{Al}$ interface. In the $\mathrm{Al}$ matrix, smaller $\mathrm{N}$ atoms diffuse faster than B atoms thus resulting in the formation of AlN at the matrix-side interface. Consequently, at the BNNT-side interface, the concentration of $\mathrm{B}$ increases thus promoting the growth of $\mathrm{AlB}_{2}$.

From the comparison of experimental results of this study with available literature data and theoretical prediction of the growth of carbides due to interaction between Al-based matrix and MWCNT reinforcement, we suggest that in the case of AlTi6 alloy at $1000{ }^{\circ} \mathrm{C}$, the dissolution-precipitation mechanism plays a leading role in the generation of rod-like $\mathrm{TiC}$ crystallites in liquid-state processing of in situ Al-TiC composites using MWCNT as a carbon source. Interaction of MWCNTs with liquid constituent of AlTi6 alloy starts from local dissolution of carbon from MWCNTs in the liquid resulting in the formation of surface defects and discontinuities in the carbon nanotubes. Next, the dissolved $\mathrm{C}$ reacts with $\mathrm{Ti}$ from the liquid $\mathrm{L}_{\left(\mathrm{Al}^{-} \mathrm{Ti}\right)}$ to form $\mathrm{TiC}$ that is heterogeneously nucleated at the tips and surface defects of MWCNTs. Such local MWCNT dissolution coupled with $M W C N T \rightarrow \mathrm{TiC}$ transformation causes fragmentation of carbon nanotubes 
whose ends present new sites for $\mathrm{TiC}$ nucleation. As soon as $\mathrm{Ti}$ from the liquid surrounding $\mathrm{TiC}$ phase is consumed, the dissolution of residual $\mathrm{Al}_{3} \mathrm{Ti}$ particles starts and new $\mathrm{Ti}$ is delivered to the surface of $\mathrm{TiC}$ crystallites until complete consumption of $\mathrm{Al}_{3} \mathrm{Ti}$ phase.

\section{Summary}

The sessile drop tests applied for investigation of hightemperature interaction between liquid oxide-free AlTi6 alloy and MWCNT substrates showed unusual wetting behavior after dispensing the drop from a ceramic capillary at $800{ }^{\circ} \mathrm{C}$. The drop jumping observed in subseconds of the first contact with the substrate was suggested to be related with the combined effect of gas release from the substrate, its lotus leaf-like surface structure, and deformation of thin MWCNT paper. Non-wetting behavior of AlTi6 alloy in this study was found to be apparent because molten AlTi6 alloy infiltrates the whole thickness of the MWCNT substrate causing its detachment from the alumina support, not wettable by liquid AlTi6 alloy.

Structural characterization of metal-infiltrated region evidenced in situ formation of Al-TiC composite in which most TiC precipitates have a rod-like morphology. For the applied liquid-phase process in the sessile drop tests, the dissolutionprecipitation mechanism has been suggested to be dominant in the generation of rod-like $\mathrm{TiC}$ crystallites growing on the tips of MWCNTs fragmented due to their local dissolution and $M W C N T \rightarrow$ TiC transformation.

\section{Acknowledgments}

The financial support from the National Centre for Research and Development in the frame of "Advanced Materials and Technologies for Their Manufacture,” Project No. POIG.01.01.0200-015/09-00.

\section{Open Access}

This article is distributed under the terms of the Creative Commons Attribution 4.0 International License (http://creativecommons.org/ licenses/by/4.0/), which permits unrestricted use, distribution, and reproduction in any medium, provided you give appropriate credit to the original author(s) and the source, provide a link to the Creative Commons license, and indicate if changes were made.

\section{References}

1. J. Sobczak, N. Sobczak, R. Asthana, A. Wojciechowski, K. Pietrzak, and D. Rudnik, ATLAS of Metal-Matrix Composite Structures, Motor Transport Institute, Foundry Research Institute, Cracow, 2007

2. Y. Huang, Q. Ouyang, D. Zhang, J. Zhu, R. Li, and H. Yu, Carbon Materials Reinforced Aluminum Composites: A Review, Acta Metall. Sin., 2014, 27(5), p 775-786

3. X. Qu, L. Zhang, M. Wu, and S. Ren, Review of Metal Matrix Composites with High Thermal Conductivity for Thermal Management Applications, Prog. Nat. Sci. Mater. Int., 2011, 21, p 189-197

4. N. Sobczak, J. Sobczak, S. Seal, and J. Morgiel, TEM Examination of the Effect of Titanium on the Al/C Interface Structure, Mater. Chem. Phys., 2003, 81, p 319-322

5. E. Neubauer, M. Kitzmantel, M. Hulman, and P. Angerer, Potential and Challenges of Metal-Matrix-Composites Reinforced with Carbon
Nanofibers and Carbon Nanotubes, Compos. Sci. Technol., 2010, 70, p 2228-2236

6. S.R. Bakshi, D. Lahiri, and A. Agarwal, Carbon Nanotube Reinforced Metal Matrix Composites-A Review, Int. Mater. Rev., 2008, 55(1), p 41-64

7. E. Landree, F. Nihey, and S. Iijima, Heterostructures of Single-Walled Carbon Nanotubes and Carbide Nanorods, Science, 1999, 285(5434), p 1719-1722

8. L. Ci, Z.Z. Ryu, N.Y. Jin-Phillipp, and M. Rühle, Investigation of the Interfacial Reaction Between Multi-walled Carbon Nanotubes and Aluminum, Acta Mater, 2006, 54(20), p 5367-5375

9. T. Laha, S. Kuchibhatala, S. Seal, W. Li, and A. Agarwal, Interfacial Phenomena in thermally Sprayed Multiwalled Carbon Nanotube Reinforced Aluminium Nanocomposite, Acta Mater., 2007, 55, p 1059-1066

10. H. Kwon, D.H. Park, J.F. Silvain, and A. Kawasaki, Investigation of Carbon Nanotube Reinforced Aluminum Matrix Composite Materials, Compos. Sci. Technol., 2010, 70, p 546-550

11. A.B. Elshalakany, T.A. Osman, A. Khattab, B. Azzam, and M. Zaki, Microstructure and Mechanical Properties of MWCNTs Reinforced A356 Aluminum Alloys Cast Nanocomposites Fabricated by Using a Combination of Rheocasting and Squeeze Casting Techniques, Hindawi, J. Nanomat., 2014, 4, p 1-14

12. A.D. Moghadam, E. Omrani, P.L. Menezes, and P.K. Rohatgi, Mechanical and Tribological of Self lubricating Metal-Matrix Nanocomposites Reinforced by Carbon Nanotubes (CNTs) and Graphene (review), Composites B, 2015, 77, p 402-420

13. S.F. Bartolucci, J. Paras, M.A. Rafiiee, J. Rafiee, S. Lee, D. Kapoor, and N. Koratkar, Graphene-Aluminum Nanocomposites, Mater. Sci. Eng. A, 2011, 528, p 7933-7937

14. J. Shin, K. Choi, S. Shiko, H. Choi, and D. Bae, Mechanical Damping Behaviour of Al- $\mathrm{C}_{60}$-Fullerene Composite with Supersaturated Al-C Phases, Composites B, 2015, 77, p 194-198

15. Z. Tan, Z. Li, G. Fan, Q. Guo, X. Kai, G. Ji, L. Zhang, and D. Zhang, Enhanced Thermal Conductivity in Diamond/Aluminium Composites with a Tungsten Interface Nanolayer, Mater. Des., 2013, 47, p 160-166

16. M. Caccia, A. Rodriguez, and J. Narciso, Diamond Surface Modification to Enhance Interfacial Thermal Conductivity in Al/Diamond Composites, J Microsc. Oxf., 2014, 66(6), p 920-925

17. A. Olszówka-Myalska, J. Myalski, and J. Chrapoński, Influence of Casting Procedure on Microstructure and Properties of $\mathrm{Mg}$ AlloyGlassy Carbon Particle Composite, Int. J. Mater. Res., 2015, 106(7), p 741-749

18. N. Sobczak, Improvement of Wetting and Bonding of Dissimilar Materials, NATO Asi 3 High Tech., 1998, 58, p 27-42

19. R. Asthana, N. Sobczak, Wettability, Spreading, and Interfacial Phenomena in High-Temperature Coatings, JOM, 52(1), p 1-19 (2000). http:// www.tms.org/pubs/journals/JOM/0001/Asthana/Asthana-0001-text.html

20. N. Sobczak, Z. Gorny, M. Ksiazek, W. Radziwill, and P. Rohatgi, Interactions Between Porous Graphite Substrate and Liquid or Semiliquid Aluminium Alloys Containing Titanium, Mater. Sci. Forum, 1996, 217-222, p 153-158

21. N. Sobczak, Effect of Alloying Elements on Wettability and Interfaces in Aluminium-Carbon System, Proceedings of the International Conference Light Alloys and Composites, 1999 Zakopane, Poland, p 341-349

22. N. Sobczak, R. Nowak, W. Radziwill, A. Kudyba, A. Wojciechowski, and D. Rudnik, Effect of Carbon Coating on Wetting and Bonding of $\mathrm{Al} / \mathrm{Al}_{2} \mathrm{O}_{3}$ and AlTi6/ $/ \mathrm{Al}_{2} \mathrm{O}_{3}$ Couples, Polish Ceram. Bull., 2005, 80, p 669-676

23. K. Landry, S. Kalogeropoulou, and N. Eustathopoulos, Mater. Sci. Eng. A, 1998, 254, p 99-111

24. K. Landry, S. Kalogeropoulou, N. Eustathopoulos, Y. Naidich, and V. Krasovsky, Scr. Mater., 1996, 34, p 841-848

25. P.J. Bunyan and S.H. Huo, Electromagnetic Enhancement of Wetting in the $\mathrm{Al}-\mathrm{Al}_{2} \mathrm{O}_{3}$ and Al-Graphite Systems, Proceedings of the International Conference on Advanced Composites'93, T. Chandra and K. Dhingra, Ed., 1993, p 1009-10014

26. S. Seal, T.L. Barr, N. Sobczak, and S.J. Kerber, Microscopy and Electron Spectroscopic Study of the Interfacial Chemistry in Al-Ti Alloy/Graphite Systems, J. Mater. Sci., 1998, 33, p 4147-4158

27. S. Seal, T. Warwick, N. Sobczak, and J. Morgiel, A scanning Photoemission Microscope (SPEM) to Study the Interface Chemistry of AlTi/C System, J. Mater. Sci. Lett., 2000, 19, p 123-126 
28. V. Yamamoto, D. Alizadeh, L. Zhang, H.M. Manohara, M.J. Bronikowski, and B. Badie, Multi-walled Carbon Nanotube (MWCNT) Synthesis, Preparation, Labeling, and Functionalization 2010, Methods Mol. Biol., 2010, 651, p 307-317. doi:10.1007/978-1-60761-786-0_18

29. N. Sobczak, R. Nowak, W. Radziwill, J. Budzioch, and A. Glenz Experimental Complex for Investigations of High-Temperature Behaviour of Molten Metals in Contact with Refractory Materials, Mater. Sci. Eng. A, 2008, 495, p 43-49

30. L. Liggieri and A. Passerone, An Automatic Technique for Measuring the Surface Tension of Liquid Metals, High Temp. Technol., 1989, 7, p 80-86

31. ASTRA Reference Book, IENI, Report, Oct. 2007

32. E. Asedebega-Niedo, M. Perez-Caadenas, J. Carter, J.A. Anderson, and A. Guerrero-Ruiz, Preparation and Surface Functionalization of MWCNTs: Study of the Composite Materials Produced by the Interaction with an Iron Phthalocyanine Complex, Nanosc. Res. Lett., 2011, 6, p 353

33. S. Jin, P. Shen, D. Zhou, and Q. Jiang, Self-propagating HighTemperature Synthesis of Nano-TiCx Particles with Different Shapes by Using Carbon Nano-tube as C Source, Nanosc. Res. Lett., 2011, 6(515), p 1-7

34. S.R. Shatynski, The Thermochemistry of Transition Metal Carbides, Oxid. Met., 1979, 13(2), p 105-118

35. N. Sobczak, Effects of Titanium on Wettability and Interfaces in Aluminum/Ceramic Systems, Ceram. Trans., 2005, 146, p 83-90

36. H. Dai, E.W. Wong, Y.Z. Lu, S. Fan, and C.M. Lieber, Synthesis and Characterization of Carbide Nanorods, Lett. Nat., 1995, 375, p 769772

37. X. Li, A. Westwood, A. Brown, R. Brydson, B. Rand, and A. Convenient, General Synthesis of Carbide Nanofibres Via Template Reactions on Carbon Nanotubes in Molten Salt Media, Carbon, 2009, 47, p 201-208

38. C.H. Liang, W. Pyda, and J. Morgiel, Nano-TiC Obtained Through a Reaction of MWCNTs with $\mathrm{Zr}(\mathrm{Y}, \mathrm{Ti}) \mathrm{O}_{2}, J$. Microsc., 2010, 237(3), p $487-496$

39. D. Lahri, V. Singh, S. Seal, Y. Chen, and A. Agarwal, Insight into Reactions and Interface Between Boron Nitride Nanotube and Aluminium, J. Mater. Res., 2012, 27, p 2760-2770 